\title{
Technology Policies and Learning with Imperfect Governance
}

\author{
Mushtaq H. Khan ${ }^{1}$ \\ (in Stiglitz, Joseph and Justin Yifu Lin (eds) The Industrial Policy Revolution I. The Role of
} Government Beyond Ideology, London: Palgrave 2013. pp. 79-115)

Developing countries can grow rapidly by absorbing known technologies from more advanced countries. Yet developing countries often find it difficult to absorb relatively simple technologies even when they have the resources to buy the relevant machines and have workers with the appropriate levels of formal education who are willing to work for relatively low wages. The reasons are often contracting problems that prevent critical investments being organized. A number of potentially relevant contracting failures are well known but a particularly important one is underemphasized. Developing countries typically lack the organizational and technological capabilities embedded in firms that are necessary for using new technologies to produce competitive products. Building organizations that can competitively use the new technologies is a difficult task that is subject to significant contracting failures. Developing the appropriate organizational capabilities involves the exertion of significant effort in the acquisition of tacit knowledge, a process that is difficult to observe and control. This exposes financiers to significant contracting risks that can result in non-investment or the failure to achieve competitiveness. In general, solutions to contracting failures require properly designed corrective policies and appropriate governance capabilities on the part of the state. Developing countries typically have limited governance capabilities and limited potential of developing these capabilities in every direction. It is therefore important to identify the precise contracting failures that are most important to address and to design policies that have the greatest chance of being implemented given existing governance capabilities and the feasible improvements in these capabilities. The fit between problems, policies and capabilities can explain why some countries or sectors can do well even when overall governance capabilities are weak.

Technology policies (often also described as industrial policies) describe a range of policies that could in principle address a wide variety of contracting failures using instruments that assist the parties involved to move closer to desirable outcomes. However, the problem is that while private contracting in developing countries is subject to many contracting failures, their states also lack many of the critical enforcement and governance capabilities required to effectively implement many corrective policies. The general observation is that developing countries have weak or imperfect governance, and this often leads to the policy advice that they should steer clear of industrial policies. This avoids the problem of government failures but it obviously does not make the underlying market failures disappear. However, the

\footnotetext{
1 Department of Economics, SOAS, University of London, email: mk100@soas.ac.uk, web: http://www.soas.ac.uk/staff/staff31246.php. I would like to thank Pranab Bardhan and Joe Stiglitz for comments on an earlier version of the paper.
} 
historical evidence makes it painfully obvious that given imperfect governance, not all technology policies are likely to achieve the desired results. To be effective, technology policies have to be designed to be effective given the institutions and governance capabilities of particular states. This implies that the relevant contracting failures have to be properly identified to determine the problems policies have to address. Secondly, there are usually many possible responses to any particular contracting problem, and not all of them may be equally enforceable in every context. The second step is therefore to select the response that is most likely to be effective given the relative power of the interests affected by the policy in the local context. Finally, for policies to be successful, some governance capabilities may also need to be developed in critical agencies to monitor and enforce particular policies.

Understanding the interrelationships between these factors can help to explain why some countries have done rather better with industrial policies than others in contexts of weak governance. While all developing countries are far removed from the textbook requirements of 'good governance' (strong enforcement of a rule of law, government accountability and well-defined property rights), some have been better or luckier in adopting policies that were more effective in the context of their governance, and better at developing the capabilities of critical agencies that enabled these strategies to be effectively implemented. These insights can help us to design better technology policies in countries that have performed less well. Although the policy solutions for addressing many technology-adoption problems can appear to be quite similar (for instance providing temporary subsidies to firms), the governance conditions for ensuring their success can be quite different depending on the underlying contractual problem that the subsidy aims to resolve and the specific policy solutions adopted in response.

The literature on technology and industrial policies identifies a number of different contracting problems affecting technology adoption. It is likely that a country faces more than one problem at any one time. However, policy needs to ensure that the most general problems (the ones that affect all or most cases of technology acquisition) are addressed first. Unfortunately, the most general problem is not necessarily the easiest to solve in terms of appropriate policy design and the requisite governance capabilities. At the heart of the technology acquisition problem is the paradox that low-wage countries are unable to achieve competitiveness using freelyavailable technologies that they should in principle be able to use. The reason for this is that competitiveness depends not just on wages but also on the productivities of labour, input usage and capital equipment. The productivity of all factors depends not just on the formal technical knowledge of workers and managers but also and primarily on the tacit knowledge of organizational and technological capabilities that is embedded in the routines of the production team as a whole.

The technological capabilities of workers and managers refer to their abilities to use machines and technologies properly. These capabilities are partly based on formal education and training but can also depend on on-the-job learning-by-doing. In addition, the productivity of workers, the productivity of input usage and that of capital equipment depends on the organization as a whole working effectively as a team. This is why organizational capabilities are possibly even more important for the overall productivity and competitiveness of the firm. Organizational capabilities are embedded in the routines of the organization, and these organizational structures 
are a form of tacit knowledge that the organization acquires, again often through learning-by-doing and experimentation. Without these technological and organizational capabilities, productivity levels are typically too low for the developing country to competitively engage in production, even if it acquires the machines and has workers and managers who have the formal knowledge that is required for the use of the technology. This is true even for relatively low technology production processes. The acquisition of tacit knowledge through learning-by-doing is one of the most general problems affecting almost all areas of technology acquisition in developing countries and is subject to important contracting failures. In the absence of solutions to these problems, a new firm or an entire country can find its technology acquisition strategies blocked.

It is widely recognized that the acquisition of tacit knowledge requires learning-bydoing. However, the problem is that 'doing' without a large element of effort is not likely to generate much learning. Effort is obviously important in the learning-bydoing processes through which individual workers improve their productivity. But effort is particularly important in developing organizational capabilities because the learning that is involved here involves the organization and reorganization of firms as complex organizations that can work smoothly to produce competitive products. When infant industries fail to graduate into productive enterprises despite decades of 'doing' financed by different types of implicit subsidies, it is almost always because there was a failure of organizational learning. The continuous restructuring and finetuning of organizations to achieve high levels of productivity and competitiveness is a high effort activity that involves risks and costs for managers and other stakeholders. Change is painful and has distributive implications that are likely to be resisted. Without pressure and even compulsion, doing can continue indefinitely without any organizational learning happening.

The obvious conclusion is that successful learning requires the exertion of a high level of effort in the learning process, particularly by management. The effort here refers to the effort in experimenting with and achieving the organizational design and work practices that achieve the required levels of productivity. Effort here does not refer to the effort exerted in the normal production process. The problem is that the appropriate incentives and compulsions for ensuring high levels of learning effort are difficult to enforce. This is the contracting failure that constrains private money flooding in to finance investments in learning-by-doing. But public financing is also likely to be largely wasted if it does not address the underlying contracting problem in ways that can be effectively enforced. This is likely to be the most general contracting problem affecting technology adoption. Even when developing countries succeed in acquiring and installing production facilities using technologies that are theoretically appropriate, they often find their levels of productivity are too low to achieve competitiveness. Missing tacit knowledge about how to organize the relevant production processes is usually at the heart of the problem. If the problems constraining the acquisition of technological and organizational capabilities are not solved, solutions to other aspects of the technology adoption problem are not likely to be effective.

Financing learning-by-doing strategies effectively requires appropriate governance capabilities on the part of the state. Discussions about the governance conditions required for effective technology policies used to be dominated by the experiences of 
East Asian countries, and particularly South Korea. In South Korea, high levels of effort in the learning supported by its industrial policy in the decades after the 1960s were ensured by credible state sanctions on non-performing enterprises. This required bureaucratic capabilities to monitor performance and withdraw support from nonperformers and it also required a business sector that could not make political alliances to protect their temporary 'learning rents' (Khan 2000b). This combination of bureaucratic and political conditions is typically lacking in most developing countries. If the South Korean instruments for financing learning were the only ones available, we would have to reach the conclusion that technology policies were not feasible in most developing countries. However, the experience of successful sectors in developing countries with relatively weak governance capabilities shows that other types of financing can be effective in apparently adverse governance conditions. The critical requirement is that institutional and political conditions have to be appropriate for creating credible incentives and compulsions for high levels of effort during the learning process given specific financing instruments. This is illustrated with reference to examples of successful learning-by-doing and technology adoption in India and Bangladesh. The policy conclusion is that technology policy is possible in countries with 'imperfect' governance conditions, but only if the financing instruments and sectors supported are compatible with the institutional and political conditions in the country.

Section 1 sets out a simple model showing how effort in learning determines the likelihood of acquiring the tacit knowledge embedded in organizations that achieve high levels of productivity and competitiveness. For investments in learning to achieve these results, a set of specific contracting failures have to be solved. Attempts to solve other contracting failures that can also plausibly constrain technology acquisition are unlikely to be effective without solutions to this fundamental problem. Section 2 discusses the variables that affect the likelihood of high levels of effort in the learning process. This part of the analysis draws on the concept of the political settlement that describes an equilibrium distribution of power between organizations of different types (Khan 2010, 2012). Section 3 summarizes two cases of successful catching up from India and Bangladesh to demonstrate the general argument. The conclusion summarizes the policy messages implied by the analysis.

\section{Tacit knowledge, Organizational Capabilities and Competitiveness}

Developing countries trying to absorb new technologies are attempting to produce products that already have a global price for different qualities set by the leading countries using these technologies. The machines and technologies for producing these products are likely to be well known but there may be many variants of competitive organizations using these technologies in different leading countries. These organizational variants reflect differences in local conditions, habits of work of the workforce, infrastructural constraints that have to be dealt with and so on, but in every case, the existing organizations define levels of quality and price that the catching-up country has to match. Protecting domestic markets, granting export subsidies or implicit subsidies of different types can provide infant industries in developing countries with the 'loss-financing' to engage in production and learningby-doing, but unless competitiveness catches up, these strategies become unsustainable in terms of the accumulating subsidy cost. 
Competitiveness depends on both price and quality. For a catching-up firm to graduate out of subsidies, it has to achieve a price-quality mix that is globally competitive. Once this is achieved, explicit or implicit subsidies are no longer required. Products can be defined as combinations of characteristics. Broad clusters of characteristics define a particular type of product, but any product also has detailed characteristics of reliability, performance, attractiveness, design and a range of other functions that can distinguish the 'quality' of particular products within a broad group (Lancaster 1966; Sutton 2005, 2007). Products can therefore be indexed by quality, with higher quality cars (for instance) being (in general) more difficult and more expensive to produce, but also attracting a higher price that is high enough to make it worthwhile for producers to always seek to improve product quality.

Developing countries are generally not in the business of innovating new products. This is a relatively small part of the growth process even in middle income developing countries. Rather, the most important problem for developing countries is to learn how to produce an improving range of products from the qualities that already exist, at a price that is equal to or lower than the ones already available. If a country can produce an existing product of a particular quality at a price lower than that currently prevailing it has a chance of capturing markets from already established producers or extending the market to new consumers. Lower quality products are generally easier to produce, but for any quality level a maximum price is defined in global markets and a new entrant will not be able to sell its products without a subsidy if it cannot match this price. The problem for developing countries is that they are often unable to produce products of the requisite price-quality combination even when their wages are lower than their competitors and even when they aim at relatively low qualities and technologies.

Higher quality products have, by definition, a higher selling price, so in general they allow either a higher wage or a higher profit mark-up or both. Improving the quality of products is therefore a way of achieving wage and profit growth. Secondly, productivity growth is likely to be higher in higher quality products to the extent that these are still the subject of innovation in advanced countries. Developing countries that shift to higher qualities and build the organizations that can effectively produce these qualities are therefore likely to enjoy faster incremental productivity growth by being able to copy or adapt these innovations. At the same time, lower quality products can become inferior goods as world incomes increase, and global consumers are likely to gradually shift away from goods of lower quality. Finally, lower quality products are more likely to be targeted as entry points by even poorer countries creating gradual downward pressure on prices. It is therefore both socially and privately desirable to produce the highest quality products that are feasible.

The catching up problem can therefore be defined as a) entering globally competitive production for a variety of products at the highest feasible levels of quality, b) spreading these organizational capabilities broadly to create jobs across the working population and c) systematically moving up the quality ladder across product categories to achieve wage growth and sustained productivity growth. In reality, many developing countries struggle to produce anything competitively. Some produce a very limited range of competitive products but of low quality and find it difficult to move up the product and quality ladder. A few more advanced developing countries produce a range of competitive products, some of higher quality, but face challenges 
in achieving quality improvements and even greater challenges in entering new product ranges.

The essential features of the catching-up problem can be described using a simple mark-up pricing model for products of a given quality. The current global price of a particular product of quality Q is set by its cost of production in the country that is currently the global production leader. The unit price can be arithmetically broken down into the unit labour cost plus the unit input cost plus the unit amortized capital cost representing the unit cost of machinery and buildings. This is shown in eq. [1]:

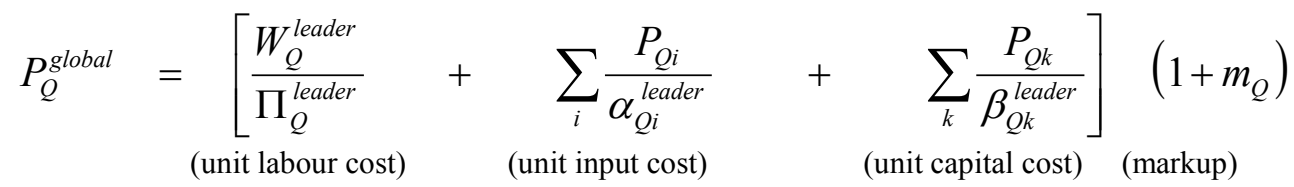

To simplify the notation we do not denote products and simply refer to a particular quality indexed by $\mathrm{Q}$, so $\mathrm{Q}+1$ represents a higher quality product compared to $\mathrm{Q}$. $P_{Q}^{\text {global }}$ is the international price of a particular product of quality Q. $W_{Q}^{\text {leader }}$ is the wage level in the leading country producing the product of quality $\mathrm{Q} . \Pi_{Q}^{\text {leader }}$ is the productivity of labour in this activity in the leading country, measured by the output per person in this activity. The first term on the right hand side is therefore the unit labour cost.

The second term is the unit input cost. The production of the product requires $i$ inputs as raw materials or semi-manufactured inputs. To simplify, we assume these inputs are globally traded, each with a global price of $P_{Q i}$. The efficiency with which inputs are used is measured by the productivity of input use (output per unit input). In the leading country, the input productivities of each of the $i$ inputs are represented by $\alpha_{Q i}^{\text {leader }}$. Input productivity primarily measures wastage and input loss due to rejected final products. In many production processes this is a critical determinant of competitiveness.

The third term refers to the unit 'capital' cost attributable to the cost of machinery and buildings. There are $k$ inputs of this type, and the most important elements are usually machines, which have a globally traded price, though land and buildings can also be significant cost components in some cases. The unit cost of capital is determined by the fraction of each component of these capital costs attributed to the particular period of production, represented by $P_{Q k}$ divided by the output-capital ratio for each type of capital (the productivity of capital) measured by $\beta_{Q k}^{\text {leader }}$. As the capital stock that is available in each period is fixed, the output-capital ratio depends critically on the scale of production that determines capacity utilization. The higher the output achieved with any given capital stock, the higher the productivity of capital measured by each $\beta_{Q k}^{\text {leader }}$. Low capital productivity could therefore be the result of a lack of technological capabilities on the part of the workforce resulting in improper use of machinery but it could also reflect spare capacity if machines and fixed assets are underused because of a suboptimal scale of production. Finally, the mark-up determining price is set at $m_{Q}$ 
In the same way, the cost of production (in a common currency) in the developing country is the domestic cost $C_{Q}^{\text {domestic }}$ for the product of quality $\mathrm{Q}$, given by an exactly equivalent equation but with the appropriate domestic productivities and prices:

$$
C_{Q}^{\text {domestic }}=\left[\frac{W_{Q}^{\text {domestic }}}{\Pi_{Q}^{\text {domestic }}}+\sum_{i} \frac{P_{Q i}}{\alpha_{Q i}^{\text {domestic }}}+\sum_{k} \frac{P_{Q k}}{\beta_{Q k}^{\text {domestic }}}\right]\left(1+m_{Q}\right)
$$

The follower country achieves competitiveness when its $C_{Q}^{\text {domestic }} \leq P_{Q}^{\text {global }}$. The globally traded prices of inputs and machinery are typically similar in the follower and leader countries but wages and some input costs are likely to be lower in the former. The cost of borrowing, which affects the amortized cost of capital, may be higher in the follower (reflecting a higher risk premium), but the difference may not be very significant. It may therefore appear that the developing country should be able to achieve competitiveness for many simple technologies for which the appropriate formal skills exist since its wage level is lower: $W_{Q}^{\text {domestic }}<W_{Q}^{\text {leader }}$, and most other prices are either similar (globally tradable inputs and machinery) or lower (possibly for some non-tradable inputs like land and buildings). But in fact developing countries usually cannot break into the production even of relatively low technology (low quality) products because they typically suffer from significant productivity disadvantages that more than negate their wage and other cost advantages. Output per person is generally much lower, $\Pi_{Q}^{\text {domestic }}<\Pi_{Q}^{\text {leader }}$, as are many input and capital productivities, $\alpha_{Q i}^{\text {domestic }}<\alpha_{Q i}^{\text {leader }}$ and $\beta_{Q k}^{\text {domestic }}<\beta_{Q k}^{\text {leader }}$. These productivity differentials explain why despite low wages, the follower country typically has a higher cost of production than the global price even for relatively low technology products.

It may appear that a low wages could compensate for these productivity differentials, but in reality that wage may have to be much lower than is feasible. A more profound problem is that in many cases, even zero wages may not be able to compensate for a lower efficiency of input and capital productivity. This is because inputs and capital equipment have global prices that have to be paid. If $\alpha_{Q i}^{\text {domestic }}<\alpha_{Q i}^{\text {leader }}$ for expensive globally traded inputs, the greater wastage of inputs alone could result in a higher domestic cost of production even if the domestic unit labour cost could be pushed to zero. This is why efficiency in controlling the wastage of inputs and reducing product rejection is often a critical variable in achieving competitiveness. In addition, the productivity of critical capital equipment is often lower, with $\beta_{Q k}^{\text {domestic }}<$ $\beta_{Q k}^{\text {leader }}$ as a result of machinery not being properly set up, or the optimal scale of production not being achieved. Indeed, a small disadvantage in these productivity variables across a number of inputs and types of capital could mean that even with zero wages, the cost of production in the developing country may be higher. In fact, wages are typically a relatively small part of the cost of production even in labourintensive manufacturing processes. Competitiveness, even in low technology products, therefore depends more on the level and growth of productivity rather than on cost advantages. 
While it is conceptually useful to distinguish between labour, input and capital productivity, all of these productivity measures are affected by the ways in which production is set up and organized by the management and workers operating machinery of a specific type. The productivity of all inputs including labour depends on how effectively the production process is organized. Output per person, $\Pi_{Q}$, depends on a variety of economy-wide and firm-level factors. The economy-wide determinants of firm labour productivity include the quality of public goods and utilities including the quality of education, infrastructure and the reliability of utility supplies. Firm labour productivity is also determined by firm-level variables like the capital equipment used by labour and the skill and experience of the workforce and management. The technological capabilities of workers are important determinants of firm-level productivity. These depend on their formal training and education but also on their tacit knowledge of operating equipment effectively as a result of learning-bydoing. However, an even more important determinant of firm-level labour productivity is the organization of the firm: how teams are set up to ensure a smooth flow of production, how machinery is set up to reduce bottlenecks, how management systems are set up to solve problems and so on. These organizational capabilities are also the result of effective learning-by-doing that results in the evolution of a work organization that achieves high labour productivity.

In the same way, the efficiency of input use, $\alpha_{Q i}$ depends on the same economy-level variables determining the skills and education of the workforce, as well as firm-level variables like the type and sophistication of the capital equipment used and the technological skills of the workforce using this equipment, based on both formal skills and tacit knowledge. In addition, the firm-level organization of production is again often of critical significance. Organizational design is critical for limiting the wastage of raw materials and for maintaining quality so that final products are not rejected, thereby maintaining input productivity at a high level. Finally capital productivity also varies significantly across countries and firms even for machinery of exactly the same type. This too reflects differences in the organization of production and the skills and capabilities of the workers and managers. However, in addition capital productivity is also a function of the scale of production. For firms entering new lines of production, the scale of production can be constrained by the low competitiveness of the firm. This is because as long as a firm suffers from low labour and input productivity, it can only sell its products at a lower profit margin or at a loss. This can prevent it from expanding the scale of production, and the low capital productivity that results can further damage its competitiveness.

Thus, competitiveness and the underlying productivities that determine competitiveness are not just determined by having the right machinery for producing products of a particular quality and having workers and managers with the right levels of formal education and training. It depends more critically on the technological and organizational capabilities of the teams using the machines to produce products, and both sets of capabilities depend on the successful outcomes of difficult learning-bydoing processes. Early development theory and practice emphasized investment in modern machinery but we now know this is not sufficient without strategies for achieving competitiveness. Crippling differences in productivity persist across countries using identical machinery (Clark and Wolcott 2002; Sutton 2007). While the economy-level constraints on productivity are widely recognized, the firm-level 
technological and organizational capabilities of workers and management are probably much more important in explaining why some countries take off when they do. Takeoffs are rarely triggered by prior improvements in economy-wide infrastructural conditions, though sustaining growth clearly requires an improving efficiency in the delivery of education and infrastructure.

The importance of firm-level organizational capabilities as the critical determinant of competitiveness is based on two interrelated observations. First, there is the observation from observers of technological capabilities that much of the technological and organizational knowledge necessary for competitiveness is tacit knowledge embedded in routines (Nelson and Winter 1982; Dosi 1988; Pelikan 1988; Perez and Soete 1988). Engaging in effective productive activity requires a mix of formal or codifiable knowledge (knowledge that can be communicated in words or symbols) and uncodifiable 'knowing-how-to' knowledge that is embedded in unconscious and often complex routines. The latter is defined as tacit knowledge and the significance of its non-codified form is that acquiring this knowledge requires learning-by-doing rather than attending formal courses (Polanyi 1967). The process of learning efficient routines inevitably involves practice and the adaptation of practice to local conditions rather than reading off blueprints from a manual. Compared to the difficulty of 'acquiring' this tacit knowledge, buying the machines and setting up the factory are often much the easier parts of the process of technology acquisition and growth.

The difference between technological and organizational capabilities is often difficult to distinguish in practice because the former can depend on the latter. Technological capabilities refer to the productivity of individual workers which can depend on their tacit knowledge of how to use particular machines effectively. Organizational capabilities refer to the design of the organization that determines the productivity of each individual worker, and this also determines input and capital productivity. The organization of production refers to things such as setting up the layout of the machines so that production bottlenecks are avoided given the pace of work that can be achieved with local conditions, implementing effective quality control routines with incentives that are appropriate for local conditions, managing inventories taking into account local infrastructural constraints, meeting orders on time and so on.

The importance of the organizational capabilities of a production team as a whole becomes obvious when workers migrate from developing countries to more advanced ones. Their individual productivity jumps when they join a modern organization. In migrating to join an already efficient organization, an individual worker rapidly slots into existing routines and thereby rapidly improves their individual productivity, even in terms of the learning-by-doing that improves their individual technological capabilities. In contrast, if the whole team is operating with the routines of an inefficient organization or still experimenting with new routines, the individual productivity of each worker is likely to remain low. Evolving these routines takes effort from all the stakeholders as it involves experimentation and re-allocation of duties and responsibilities till the organization as a whole achieves competitiveness. Even relatively low-technology production of relatively low quality products like garments requires acquiring a huge amount of tacit organizational knowledge embedded in the routines of interaction between the hundreds or even thousands of workers and managers in the organization. 
Secondly, the literature on technological and organizational capability also points out that tacit knowledge is largely acquired through processes of learning-by-doing (Lall $1992,2000 \mathrm{a}, 2000 \mathrm{~b}, 2003$ ). If a firm has to engage in learning-by-doing to achieve competitiveness, the implication is that it has to begin production before it achieves competitiveness. This is very significant. Investment in a firm using new technologies in a developing country therefore requires some implicit or explicit form of lossfinancing as the organization cannot by definition achieve competitiveness for some considerable time. This marks a very significant difference between advanced and developing countries. In the former, the financing of machinery and buildings to set up production may face uncertainties in terms of markets and prices if the product is a new one, but the organizational capabilities of the firm and its workers are typically not in question. In developing countries, the markets and prices are well known by definition because the product is a well-known one, the uncertainty is about the organizational capabilities of the team attempting to produce the product. While the uncertainty faced by innovating firms in advanced countries is well understood, the uncertainty faced by learning firms in developing countries is often ignored in economic theory and policy.

In principle the lower profits or even losses that firms face during their period of organizational capability development could be privately financed as there is the potential of future profits. The absence of significant private engagement in investments in learning-by-doing in developing countries suggests the presence of important contracting failures that keeps private investors away from this difficult task. The difficulty is not surprising given that a locally specific organizational design is required to achieve competitiveness. External investors who may finance the learning have neither a blueprint of the organizational design that may work nor can they easily observe the effort the production team is putting in to achieve the competitive organization rapidly. In practice, governments in the past have therefore played a significant role in financing infant industry strategies. However, the relative paucity of successful infant industry programmes demonstrates the difficulty of getting the governance capabilities right for ensuring successful outcomes in these public financing strategies. Clearly, ensuring high levels of effort in these learning processes is by no means a simple affair.

The loss-financing required to engage in learning-by-doing depends on the gap between the domestic cost of production and the global price at that quality. The loss financing that would allow production (and learning-by-doing) to commence can be measured as a per unit 'subsidy', $s_{Q}$, which brings the initially higher domestic cost of production $C_{Q}^{\text {domestic }}$ into line with the global price $P_{Q}^{\text {global }}$. The 'subsidy' does not have to be a transfer from government and could be private loss financing in the form of investors accepting a lower mark-up or putting in additional cash to cover a period of loss-making. When the loss-financing involves a public subsidy, this can also be delivered in a variety of ways, some explicit, others more subtle. The possibilities include export subsidies, import protection, subsidized interest rates, subsidized inputs or infrastructure, or a cash subsidy. Thus a variety of financing instruments are available to enable learning-by-doing to commence, and in general we can describe these instruments as ways of providing 'rents for learning' (Khan 2000a). 
The essential features of the problem can be described by focusing on the situation where the domestic firm can produce products of quality Q, but at a higher cost than the current global price. The required effective rate of subsidy, $s_{Q}$, is given by the equality:

$$
C_{Q}^{\text {domestic }}\left(1-s_{Q}\right)=P_{Q}^{\text {global }}
$$

Inserting eq. [2] that defines $C_{Q}^{\text {domestic }}$ into this gives the required $s_{Q}$ :

$$
s_{Q}=1-\frac{P_{Q}^{\text {global }}}{\left(1+m_{Q}\right)}\left[\frac{W_{Q}^{\text {domestic }}}{\Pi_{Q}^{\text {domestic }}}+\sum_{i} \frac{P_{Q i}}{\alpha_{Q i}^{\text {domestic }}}+\sum_{k} \frac{P_{Q k}}{\beta_{Q k}^{\text {domestic }}}\right]^{-1}
$$

If follows from [4] that:

$$
\frac{\partial s_{Q}}{\partial P_{Q}^{\text {global }}}, \frac{\partial s_{Q}}{\partial \Pi_{Q}^{\text {domestic }}}, \frac{\partial s_{Q}}{\partial \alpha_{Q i}^{\text {domestic }}}, \frac{\partial s_{Q}}{\partial \beta_{Q k}^{\text {domestic }}}<0
$$

The required rate of subsidy declines if the global price rises, or if domestic labour productivity, input productivity or capital productivity rise. It follows that the more rapidly domestic labour, input and capital productivities grow, the sooner the subsidy can be removed. The subsidy per unit required for entering production is also likely to be higher for higher quality levels. Lower and higher quality versions of the same product are indexed by $\mathrm{Q}$ and $\mathrm{Q}+1$. Using [3], the per-unit subsidy required in each case is shown in equations [5] and [6].

$s_{Q}=1-\frac{P_{Q}^{\text {global }}}{C_{Q}^{\text {domestic }}}$

And

$S_{Q+1}=1-\frac{P_{Q+1}^{\text {global }}}{C_{Q+1}^{\text {domestic }}}$

Under plausible assumptions $s_{Q+1}>s_{Q}$, meaning a higher subsidy is required if a firm wants to engage in producing higher quality products. The organization required to produce a more complex product is generally also more complex. The gap in tacit knowledge is therefore likely to be greater for constructing the more complex organization. Both the gap in labour productivity and gaps in input productivities are likely to be greater in higher quality products because the latter typically require more sophisticated production routines and more sophisticated management of inputs. The greater labour and input productivity gaps between the two countries in quality $\mathrm{Q}+1$ compared to quality $\mathrm{Q}$ can be represented as a set of inequalities: 
$\frac{\Pi_{Q+1}^{\text {leader }}}{\prod_{Q+1}^{\text {domestic }}}>\frac{\Pi_{Q}^{\text {leader }}}{\Pi_{Q}^{\text {domestic }}}$ and $\frac{\alpha_{Q+1}^{\text {leader }}}{\alpha_{Q+1}^{\text {domestic }}}>\frac{\alpha_{Q}^{\text {leader }}}{\alpha_{Q}^{\text {domestic }}}$ for some or all $i$

The bigger gap in organizational knowledge for higher quality products is also likely to show up in lower initial capital productivity for higher quality products. In addition, capital productivity in higher qualities is likely to be further affected by the fact that higher quality production often requires more expensive machinery and is therefore likely to require a larger scale of production to become competitive. The low initial competitiveness of the firm can therefore create a further problem because the firm may find it difficult to achieve the scale economies to raise its output-capital ratio, implying a greater gap in capital productivity in higher quality products:

$\frac{\beta_{Q+1}^{\text {leader }}}{\beta_{Q+1}^{\text {domestic }}}>\frac{\beta_{Q}^{\text {leader }}}{\beta_{Q}^{\text {domestic }}}$ for some or all $k$

Returning to equations [1] and [2] we know that the costs of production in both countries are inversely proportional to their labour, input and capital productivities. Given the likelihood that some or all of the inequalities in [7] and [8] are likely to hold, it must be the case that

$\frac{P_{Q+1}^{\text {global }}}{C_{Q+1}^{\text {domestic }}}<\frac{P_{Q}^{\text {global }}}{C_{Q}^{\text {domestic }}}$

The inequality in [9] says that the cost of production in the developing country is greater (relative to the global price) for the higher quality product compared to the lower quality product. Using inequality [9] and comparing equations [5] and [6] it follows that a greater subsidy per unit will be required to overcome the initial competitiveness gap in the higher quality product compared to the lower quality product.

$s_{Q+1}>s_{Q}$

These results suggest a number of propositions.

Proposition 1. The loss-financing required to begin production is in general higher the higher the quality of the product and moreover, the subsidy will be required for longer as more complex organizational capabilities have to be developed.

As against this, the development of more complex organizational capabilities has a number of advantages.

Proposition 2. The production of higher quality products is desirable simply because their production adds more value relative to lower quality products. 
A further proposition is plausible. Economics textbooks often show technical progress as an outward shift of a production frontier for a country. In reality, this is misleading because improvements in technological capabilities are likely to be localized around specific technologies (Atkinson and Stiglitz 1969; Stiglitz 1987). The localization of productivity improvements is even more likely if competitiveness is embedded in the routines of particular organizations. In this case successful learning is likely to benefit the future adoption of technologies that are similar or closely related, rather than raising potential productivity across all technologies. Thus, we are likely to see 'bumpy' improvements in productivity clustered around particular technologies. This can explain why countries specialize in clusters of related products, possibly triggered by the random success of learning-by-doing in particular sectors. This is why it can be advantageous to acquire organizational capabilities in more advanced technologies producing higher quality products. Innovation in advanced countries is also more likely in higher quality products like electronics than lower quality products like garments. A follower country that has organizations capable of producing higher quality products is therefore more likely to benefit from further productivity growth by adopting incremental improvements in these products as innovation happens in more advanced countries.

Proposition 3. Learning-by-doing improves organizational capabilities for producing related products and if future productivity growth is likely to be faster in higher quality products, it is beneficial to develop more complex organizational capabilities.

The development challenge is therefore to accelerate the movement up the quality ladder subject to feasibility defined by the loss-financing capabilities of the society and its ability to solve the contracting failures that result in adverse outcomes for loss financing strategies.

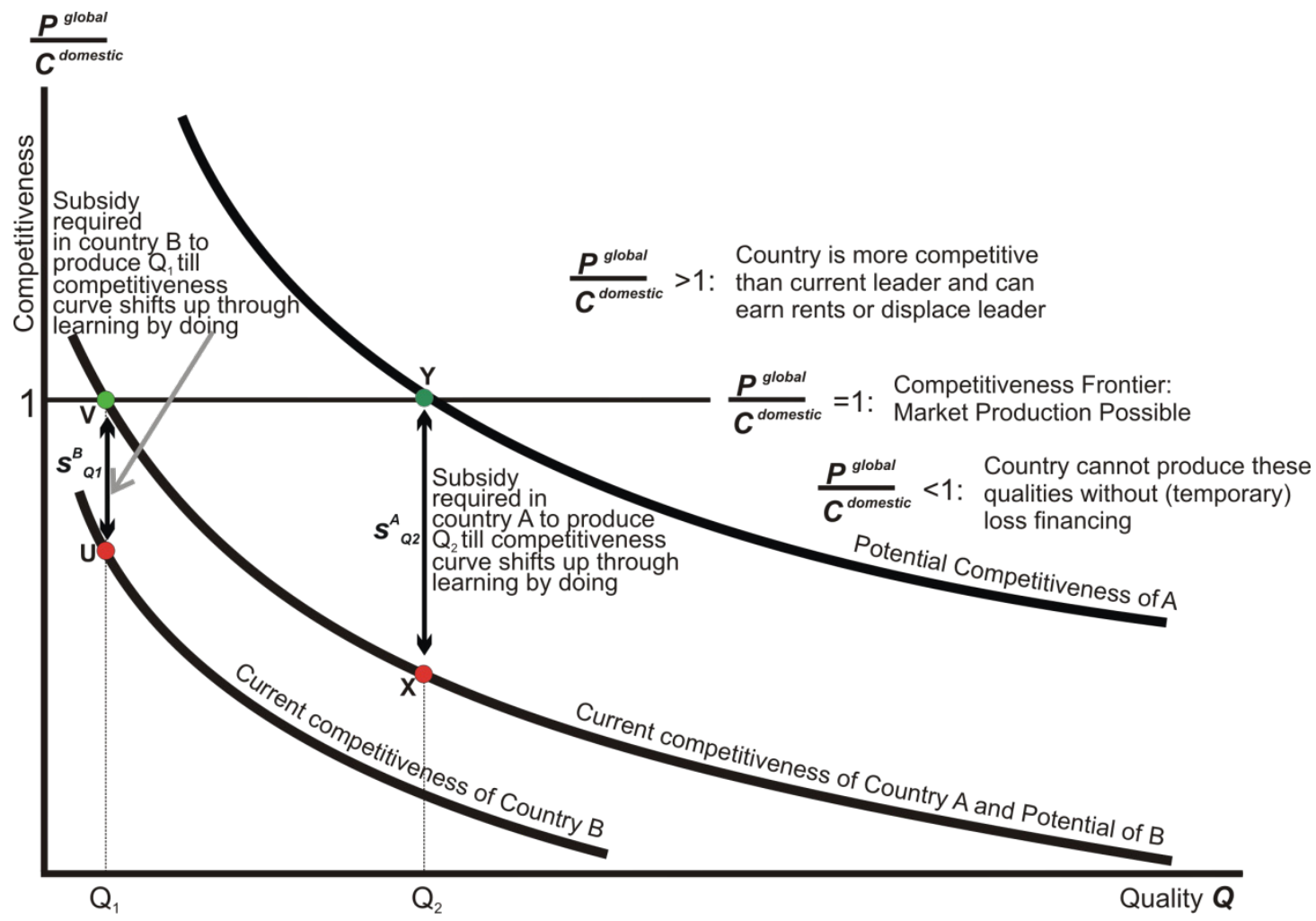

Figure 1 Loss Financing and Learning-by-doing 
Figure 1 summarizes some of the fundamental issues facing catching up and technology acquisition in developing countries. The competitiveness curve for a country summarizes its distance from global competitiveness across different quality products. The $\mathrm{x}$-axis measures the quality of the product, and the $\mathrm{y}$-axis the follower's competitiveness in producing that quality. Competitiveness is measured by the ratio $\frac{P_{Q}^{\text {global }}}{C_{Q}^{\text {domestic }}}$. A higher ratio therefore implies greater competitiveness of our country given the prices set by the leader. When this ratio is 1 or higher our country can sell a product of this quality in global markets and therefore the horizontal line at 1 can be read as the global competitiveness frontier for our country. When the ratio is less than 1 for a particular quality, our country will either not be able to produce that quality or will require (temporary) loss-financing to allow production. The required rate of 'subsidy', $s_{Q}$, equals $1-\frac{P_{Q}^{\text {global }}}{C_{Q}^{\text {domestic }}}$ in eq. [5], and is shown in Figure 1 as the gap between the global competitiveness frontier (the horizontal line at $\mathrm{P} / \mathrm{C}=1$ ) and current competitiveness at quality $\mathrm{Q}$ defined by the current competitiveness curve.

The competitiveness curve is downward sloping because although world prices of higher quality products are higher (which is why they are more desirable to produce), the cost of production in the follower country is even higher, giving it a greater disadvantage in higher quality products. The greater productivity gap in higher qualities will force market-reliant developing countries to specialize in low quality products. This may have nothing to do with the relative price of labour and capital as in standard neoclassical theory. Consistent with proposition 1, it is possible to imagine a developing country like B in Figure 1 where current organizational capabilities are so low that it cannot even produce the lowest quality of the product. In extreme cases, some developing countries may struggle to produce competitive qualities of any product. The competitiveness curve can be extended to apply to related products of different complexity. For instance, we could see different 'qualities' as parts of a vertically organized value chain. Low qualities could be low value-added parts of the value chain (like packing and assembling), medium qualities could be the production of intermediate products going into the assembly and higher qualities could be design, product development and marketing. Once again, the typical developing country would struggle to locate itself at the lower ends of the value chain where the organizational gap was less challenging, and many may not even succeed in that. At an even more general level, we could use the capability curve to think about choices across all products ranked by production complexity for which 'quality' is a proxy.

Figure 1 suggests that a country like B will need loss-financing of $s^{B}{ }_{Q 1}$ from the outset to begin production even of low-quality products $Q_{1}$ at point $U$. The success of a strategy of loss-financing would be measured by the pace at which productivity increased as a result of learning-by-doing. Successful learning-by-doing should result in the competitiveness curve moving upward till the loss-financing was no longer required at $\mathrm{V}$. Note that this does not necessarily require achieving levels of productivity equal to the leader country because the follower is likely to have a wage and cost advantage for some inputs. Sustained productivity growth is therefore likely to raise the follower's competitiveness to more than 1 , in which case the follower 
could either earn a rent (a mark-up higher than $m_{Q}$ ) at the global price or it could bid down the global price in these qualities to below a price acceptable to the leader, thereby displacing the leader from these segments of the market and achieving more sales. If the latter is the more profitable option, the developing country becomes the leader for that quality and the global price is eventually defined by the cost of production and market power of the new leader.

Finally, proposition 3 tells us that if future technological progress is localized around higher qualities and technologies, it may be desirable to further accelerate the move up the quality ladder to the points where innovation is still happening in more advanced countries. In Figure 1 the potential future productivity growth at quality $\mathrm{Q}_{1}$ may be relatively low because the technology is already mature and no further product and process innovations may happen at this quality level. Thus, for country A, which can produce $\mathrm{Q}_{1}$ competitively, the imperative may be to move to a higher quality not only to prepare for future competition from country $\mathrm{B}$, but also to enjoy faster productivity growth clustered around quality $\mathrm{Q}_{2}$. Thus, for country $\mathrm{A}$, there may be a policy justification to assist learning-by-doing around quality $\mathrm{Q}_{2}$ by organizing temporary loss-financing of $s_{Q 2}^{A}$. The challenge for A would be to go from point $\mathrm{X}$ to point $\mathrm{Y}$ to achieve competitiveness at this higher quality level. This would not only allow the country to raise its domestic value-added and living standards, it may also ensure faster productivity growth in the future.

But if temporary loss-financing can assist a country to raise its productivity through learning-by-doing, how high should a country aim? Proposition 1 tells us that given existing capabilities, the higher the quality level that the country tries to achieve, the greater the financing cost measured by $s_{Q}$. Moreover, the greater the gap with leading countries at that quality, the longer is the catching up likely to take to reach the global competitiveness frontier. As a result, trying to aim too high may involve excessively long periods of subsidization. Moreover, the competitiveness gap is only partially due to the absence of tacit knowledge. Some of the gap could also be due to levels of formal education and skills and the poor quality of economy-level public goods. If the initial gap is too big no amount of firm-level experience and learning-by-doing may remove it entirely. As both the social time preference and the cost of finance in poor countries are likely to be high, there is a limit to how high up the quality ladder it is feasible to go.

\section{Learning, Effort and Governance}

Investments in new sectors can be constrained by a variety of contracting failures. However, the contracting failures that affect learning are different from other contracting failures that can constrain investments for other reasons. These include several different types of appropriability problems limiting future profits in the presence of externalities and the costs of coordinating complementary investments. The solutions to different contracting failures can appear to be deceptively similar, for instance many of them can involve some form of subsidy or assistance. In principle, several contracting failures may also be operating simultaneously to constrain investments in technology acquisition. Nevertheless, distinguishing different contracting failures is important because the governance requirements for effectively addressing them can be markedly different. Policies supporting technology acquisition in the past often yielded poor results because the relevant contracting failures were 
not properly identified and understood. As a result, policies were not designed to be effective in solving these contracting problems with existing governance capabilities, nor were the governance capabilities necessary for the success of specific policies identified and developed.

Table 1 Major Contracting Failures Affecting Technology Acquisition

\begin{tabular}{|c|c|c|}
\hline $\begin{array}{l}\text { Contracting failures } \\
\text { Affecting Investment }\end{array}$ & Likely Policy Instruments & $\begin{array}{l}\text { Governance Capabilities } \\
\text { required for Implementation }\end{array}$ \\
\hline $\begin{array}{l}\text { Appropriability problems } \\
\text { facing investments in skills: } \\
\text { investors cannot capture full } \\
\text { benefits of training }\end{array}$ & $\begin{array}{l}\text { Public co-financing of } \\
\text { labour training and } \\
\text { investments in skills }\end{array}$ & $\begin{array}{l}\text { Capabilities in relevant } \\
\text { agencies to ensure financing } \\
\text { for training is not misallocated } \\
\text { or wasted }\end{array}$ \\
\hline $\begin{array}{l}\text { Appropriability problems } \\
\text { facing innovators: Poor } \\
\text { protection of innovation rents } \\
\text { can discourage advanced } \\
\text { technology investors }\end{array}$ & $\begin{array}{l}\text { Protection of IPRs. But } \\
\text { TRIPS may be too } \\
\text { restrictive and MNCs may } \\
\text { have weak incentives to } \\
\text { transfer technologies }\end{array}$ & $\begin{array}{l}\text { Enforcement capabilities for } \\
\text { IPRs but also policies and } \\
\text { strategies to encourage } \\
\text { technology transfer by MNCs }\end{array}$ \\
\hline $\begin{array}{l}\text { Appropriability problems } \\
\text { facing 'discovery': First } \\
\text { movers do not capture full } \\
\text { benefits of discovering } \\
\text { comparative advantage }\end{array}$ & $\begin{array}{l}\text { Subsidies for first mover } \\
\text { start-up companies in new } \\
\text { sectors }\end{array}$ & $\begin{array}{l}\text { Capability to make subsidies } \\
\text { time limited }\end{array}$ \\
\hline $\begin{array}{l}\text { Failures of Coordination: } \\
\text { Complementary supporting } \\
\text { sectors do not develop, } \\
\text { constraining investment }\end{array}$ & $\begin{array}{l}\text { Indicative or incentivized } \\
\text { strategies for coordinating } \\
\text { investments }\end{array}$ & $\begin{array}{l}\text { Significant governance } \\
\text { capabilities required to } \\
\text { coordinate and discipline } \\
\text { investments across sectors }\end{array}$ \\
\hline $\begin{array}{l}\text { Problem of Contracting } \\
\text { High Effort in Learning: } \\
\text { Financing technological- } \\
\text { organizational learning fails } \\
\text { because of low effort }\end{array}$ & $\begin{array}{l}\text { Public co-financing or } \\
\text { sharing of risks of } \\
\text { financing the learning of } \\
\text { tacit technological and } \\
\text { organizational capabilities }\end{array}$ & $\begin{array}{l}\text { Financing instruments must be } \\
\text { compatible with governance } \\
\text { capabilities to ensure credible } \\
\text { compulsions for high effort } \\
\text { learning-by-doing }\end{array}$ \\
\hline
\end{tabular}

Source: Author

Table 1 outlines a number of critical contracting failures affecting technology acquisition, the likely policy responses and the governance capabilities required to make the policies effective. Most of these contracting failures have been discussed in the literature but the differences in the governance capabilities required to address them have not received sufficient attention (Khan 2009). The positive externalities of investments in skills can result in an appropriability problem for investors and underinvestment in skills (Dosi 1988; Khan 2000a). Corrective policy involves subsidizing skills development and the required governance capabilities are to monitor outcomes and withdraw public funding if expected outcomes are not achieved. Spillovers can also affect investments in innovation, which requires the temporary protection of technology rents. While this is primarily a concern for advanced countries that rely on innovation for growth, developing countries may have to protect the intellectual property rights of multinationals in order to attract advanced technology investments (Hoekman, et al. 2004). Apart from a capability to protect intellectual property rights, technology transfer also requires significant negotiating 
skills on the part of policy-makers in developing countries to negotiate technology transfer strategies with multinationals (Khan 2000a; Stiglitz 2007).

A further set of spillovers affect investments in 'discovering' new areas of comparative advantage (Hausmann and Rodrik 2003). Although the proposition that countries have hidden comparative advantages that need to be discovered is not particularly convincing, the possibility that first movers may not be able to capture the full benefits of their investment can justify subsidizing investments in new sectors. One reason that first movers may fail to get the full benefit of their discovery is that profits may be bid down by imitators whose entry pushes up wages. To the extent that this problem dampens investment in discovery, the appropriate policy response is to subsidize investments in new sectors and the governance capability required is to ensure that the subsidies are only available to reduce the costs of the start-up phase.

A further problem is that of coordination failures affecting investments across sectors (Rosenstein-Rodan 1943; Nurkse 1953; Scitovsky 1954; Murphy, et al. 1989). This problem is well-known in the development literature, but solving it is difficult and requires significant capabilities in information gathering, understanding demand and supply complementarities and implementing the coordination effectively. These capabilities are typically missing in developing countries and development planning efforts therefore usually achieve very little. Our focus is on the last of the contracting problems in Table 1, the problem of contracting high-effort learning. Solutions to all the other problems in the table presume that the technological and organizational capabilities to set up competitive organizations already exist. In reality, developing countries lack the capabilities to use modern technologies and without this, attempted solutions to other problems are unlikely to have any effect. Unfortunately, this too is a particularly difficult problem to solve. Strategies of subsidization without incentives and compulsions to induce high effort in the learning process are likely to fail.

Private investment in financing learning may be motivated by the following type of calculation: An investment of $s_{Q}$ in loss-financing has the prospect of achieving a competitiveness of $\frac{P_{Q}^{\text {global }}}{C_{Q}^{\text {domestic }}} \geq 1$ after $n$ years. As the follower country has lower wages, productivity growth could eventually result in a cost of production lower than the world price. If productivity improves sufficiently, the investor can earn a normal profit of $m_{Q}$ or even a rent in the form of a higher mark-up of $m_{Q^{\prime}}>m_{Q}$ (after $n$ years) with an expectation that the rent $m_{Q}{ }^{\prime}-m_{Q}$ will last for $x$ years. The mark-up can decline over time for a number of reasons including the entry of new firms in the sector that bids up wages. The magnitudes of $s_{Q}, n$, and if relevant, $m_{Q^{\prime}}-m_{Q}$ and $x$, and the discount rate or cost of finance facing the entrepreneur will determine whether the investment in learning-by-doing is privately profitable. Private investments in learning may happen even without the prospect of rents because the normal mark-up $m_{Q}$ may be attractive enough given the alternative opportunities of the investor even taking into account the extra investment in loss-financing. This is therefore a different problem from the discovery problem where a private investor in a new sector will not invest without a subsidy because the social benefit from discovery is always greater than the private benefit, which may even be negative. 
In the learning problem, the contracting failure is internal to the firm and its investors as the latter find it difficult to ensure effort in learning. If this problem can be solved then private investments may happen. If the contracting problem of ensuring high effort cannot be solved, public policy has to co-finance or share the risk of financing learning. However, in some cases the configuration of costs and benefits may require a higher return to justify the investment in learning than the return that is achievable even with high effort. The required higher return may not be achievable because it may not be feasible to achieve a low enough cost of production to generate the required private rents even with feasibly high effort or it may not be possible to achieve the rents for long enough because new entrants reduce the returns of the first mover by raising wages rapidly (as in the discovery model). In these cases there may be a second reason why public policy should co-finance learning and that is the social return on learning may be higher than the feasible private return. This provides additional justification for subsidizing first-movers investing in learning in a particular sector. But even in cases where investments in learning have positive spillovers for society, if the public support for learning does not solve the problem of ensuring high levels of effort the exercise as a whole is likely to fail. This is what makes the solution of the learning problem different from the solution of the pure discovery problem and other positive externality problems which only require the provision of time-bound subsidies.

Effort is important for the learning problem because the development of technological and organizational capabilities requires both time and effort. Time and effort are inversely related: the lower the effort, the longer the learning takes. In Figure 1 firms in country B may be unable to begin production at point $U$ without loss-financing, but the feasibility of the financing depends on how long firms take to go from $\mathrm{U}$ to $\mathrm{V}$, or even whether $\mathrm{V}$ will ever be reached. The rate at which the competitiveness curve rises depends on the degree of effort that is put into the learning process once loss financing allows learning-by-doing to commence. Unfortunately, disciplining the learning process is a difficult problem to solve. Without incentives and compulsions, a production team can keep on repeating procedures without the innovations and experiments that improve its productivity. This is particularly the case if the firm can make a political case for continuing with the subsidy. The political alliances of firms can make subsidy withdrawal too costly for many governments. The institutional and political background can therefore set constraints on what can be done. The 'learning' process can then continue indefinitely, as countries with infant industries that refused to grow up have discovered. Indeed, even if the learning process is just a little too slow, financing may become unviable in terms of opportunity costs. Moreover, if the public or private investors who may have financed the learning suspect its viability, they are unlikely to engage in the financing in the first place.

The time required for achieving competitiveness, defined as the break-even period $B_{t}$, can plausibly be determined by a number of variables. First, it depends on the initial gap between the country and the global leader which we can measure by the initial competitiveness gap that the subsidy $s_{Q}$ is required to cover. The greater the initial gap, the longer it will take to catch up. Second, the time required for learning depends on the effort of the participants in the learning process. This includes both the individual efforts in acquiring technological capabilities, but even more so the management effort in acquiring organizational capabilities. Whatever the initial gap, a higher effort is likely to result in faster convergence. Effort can be measured by the 
intensity of application of workers and managers to continually improve productivity. This can be observed as the rate at which managers and workers experiment with and adapt production processes to achieve improvements in productivity. As experimentation and trials impose costs on individuals, the result can be conflicts as there may be distributive implications in redefining jobs. Thus, higher levels of effort imply costs for participants and particularly for managers. As already noted, the effort referred to here is not the intensity of the work process in general, but the effort expended in learning to raise productivity. Typically, low productivity is not the effect of laziness or low effort in general on the part of the workforce (though that may be a marginal contributor) but rather of a failure of effort on the part of the production team as a whole to evolve routines and organizational structures that raise individual productivity, improve quality control, reduce the wastage of inputs, reduce bottlenecks in production and improve capacity utilization.

Finally, the break-even period can also depend on country and firm specific factors. Country specific factors refer to general levels of education, exposure to technology, the prior history of organized modern production, infrastructural quality and so on. If a country is significantly behind in its formal technological capabilities it may fail to approach required levels of competitiveness within any feasible time period. An example of this would be the absence of a sufficient number of formally trained engineers of a particular type required in the production process. Firm level factors refer to idiosyncratic differences in the quality of entrepreneurship, the quality of technicians and managers inherited by a firm and so on. These variables are summarized in eq. [11]:

$B_{t}=f\left(s_{Q}, e, C, F\right)$

The break-even period $B_{t}$ is likely to be longer the higher the initial gap in competitiveness measured by $s_{Q}$, the lower the level of effort, $e$, and if $C$ and $F$, which describe country-specific and firm-specific factors respectively are adverse. Figure 2 tracks the pace at which the competitiveness curves in Figure 1 move up as a result of different levels of effort. To simplify, we assume that the value of other variables is such that it is potentially possible for the country to achieve competitiveness in quality $Q$. At time $t=1$ country A's competitiveness is too low for it to begin the production of quality $\mathrm{Q}$ without loss-financing. The initial loss financing is $s_{Q}$ in Figure 2. If effort levels are high, the break-even period $B_{t}=\mathrm{n}$ periods. At that point, loss financing can be abandoned and indeed if improvements in productivity continue, the country may even be in a position to earn rents in subsequent periods. 


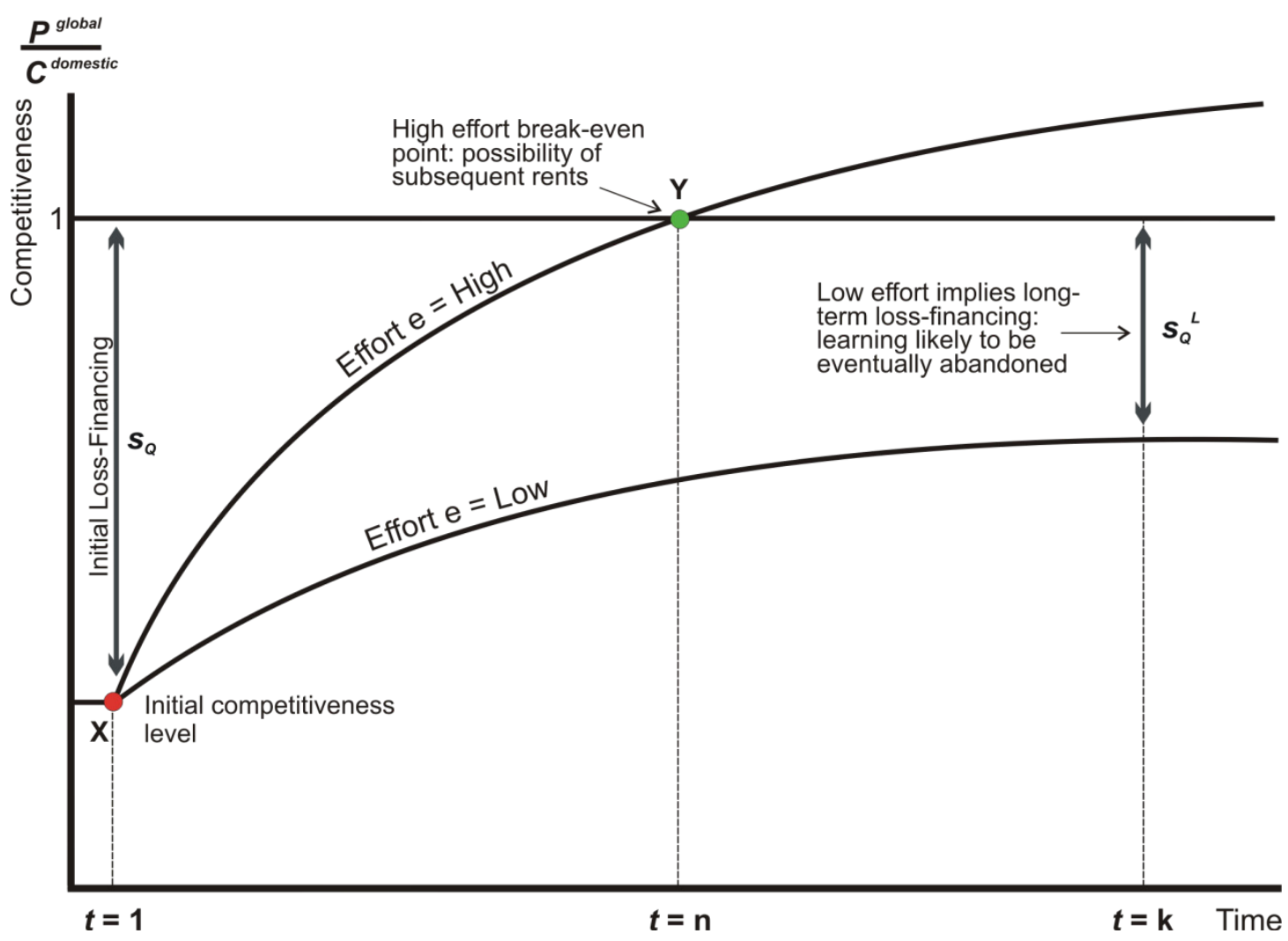

Figure 2 Effort Levels and the Viability of the Learning Process

The problem for the successful firm is that its reward for success is the loss of the rent it was getting in the form of loss-financing. The firm will have substituted a future of uncertain market profits and rents based on continuing efforts at productivity growth for a subsidy that allowed it to perform with low productivity. There is obviously an incentive compatibility problem here that can result in 'satisficing' behaviour on the part of management. The existing routines of production within the firm may be difficult and costly to change and it may be easier to spend management effort in protecting the subsidy. Not surprisingly, managers typically put a lot of effort into developing organizational capability and competitiveness when there are credible compulsions and pressures on them from outside the firm, possibly from the financing agencies. Otherwise a satisficing strategy may emerge that puts low effort into learning and more effort into protecting the subsidy. Competitiveness may never be achieved even with some productivity growth as productivity is also increasing in the leader. The infant industry will fail to grow up and eventually the catching-up strategies will have to be abandoned, but this may be many years later and managers and workers may not be too concerned about this right away.

Owner-managers financing learning-by-doing in their own organizations would not have to subcontract the management of the learning effort. However, it is unlikely that a single owner-manager will be able to finance a period of loss-making for any organization of substantial size. When external financiers are involved, they have to contract with the owner and managers of the firm to ensure high levels of effort since their returns depend on the achievement of competitiveness. The contracting problem is that the enforcement of complex contingent contracts is usually ruled out in a developing country given the weakness of contract enforcement. The overall lossfinancing $s_{Q}$ is therefore likely to be partly or entirely from public sources, 
particularly in cases where a significant organizational gap exists between the country and the market leader. The financing instruments can however vary widely, including import protection, export subsidies, subsidized credit and other forms of interventions that change relative prices and reduce or remove the losses of the learning company. However, while some level of public co-financing may be necessary, appropriate governance conditions are also required to ensure high effort. The outcome depends on the details of the financing instrument and the enforceability of the conditions critical for the success of that instrument. Enforceability depends on the governance capabilities of the relevant public agencies and the holding power of the organizations involved in the financing arrangement to resist enforcement. An important determinant of enforceability is therefore the macro-level distribution of power between firms, political organizations and enforcement agencies of different types, and we call this the political settlement (Khan 1995, 2010).

Our understanding of industrial policy has been influenced by the experience of countries like South Korea where centrally allocated learning rents achieved the rapid development of technological and organizational capabilities in the 1960s and 1970s. For a variety of historical reasons, East Asian states were untypical because their political settlements allowed the enforcement of tough conditions on domestic firms receiving support (Khan 2009; Khan and Blankenburg 2009). The financing provided to the chaebol through low interest loans, protected domestic markets and export subsidies came with conditions, for instance for achieving export targets. These conditions ensured high levels of effort because the enforcement of these conditions was credible. The state could not only withdraw subsidies; it could also re-allocate plants to different owners if they were more likely to enhance competitiveness.

Note that it was not 'good governance' that enabled the South Korean state to achieve rapid learning with its centralized industrial policy. The enforcement of performance conditions was not based on the enforcement of detailed formal contracts. Moreover, the withdrawal of subsidies or the re-allocation of plants usually did not respect property rights and the rule of law. Nor was corruption low in South Korea in the 1960 s and 1970s. What mattered was that state agencies had the capacity to enforce conditions that it was in their interest to enforce, and that had the effect of ensuring high-effort learning (Khan 1996, 2000b). The conditions themselves were subject to negotiation and the industrial policy system as a whole evolved as state agencies discovered and developed their enforcement capabilities. What is distinctive here is that firms discovered that subsidies could be withdrawn and even their plants could be re-allocated if they failed to raise their productivity. In contrast, in Pakistan at around the same period a similar system of centrally directed subsidies could not be matched with equivalent enforcement capabilities. The greater dispersion of power across political and bureaucratic organizations in this political settlement allowed firms to make alliances and satisficing rent-sharing agreements with particular political and state organizations to protect their rents (Khan 1999). Not surprisingly policy did not evolve in the direction of enforcing conditions on firms receiving support as state agencies and firms knew that setting such conditions would not be credible. As a result, technological and organizational capabilities developed much more slowly and many sectors did not achieve competitiveness at all. 


\section{Financing Learning with Imperfect Governance: Two Case Studies}

Fortunately, the South Korean model of centralized subsidy allocation is not the only one available for addressing the contracting failures affecting learning (Khan 2000a, 2000b). In political settlements less conducive for centralized monitoring and enforcement, other types of financing have proven successful in driving capability development. In the two cases examined here, learning and capability development succeeded because the design of the financing created incentives and compulsions for effort without requiring centralized monitoring and enforcement by state agencies. Nevertheless, state agencies played a critical role in setting up the financing arrangements, and the enforcement capabilities of some agencies were important in making the arrangements effective overall.

The Indian subcontinent did not perform very well with centralized industrial policy instruments in the 1960s and 1970s. In the 1980s the centralized policies started to unravel and exactly around that time a number of competitive sectors began to emerge. These instances of success are therefore often presented as success stories of liberalization, but the reality is more complex. We look at two sectors: automobiles in India and garments in Bangladesh. The transformation of these sectors into competitive ones involved new responses to contracting failures and in particular, new financing instruments emerged that created incentives and compulsions for high levels of learning effort that were credible in the political settlements of these countries.

\section{The Indian Automobile Industry}

In the 1950s and 1960s, centralized Indian industrial policy helped to build up a car industry that produced around 40,000 cars annually but of generally low quality. A protected domestic market and other implicit subsidies provided the loss-financing to low competitiveness producers that enabled them to produce Indian cars. However, low levels of compulsion for effort meant that the low-tech Ambassador never became a globally competitive product. In the 1980s, the apparatus of centralized industrial policy began to unwind, and at the same time, the sector went through dramatic changes. Quality and competitiveness began to rapidly improve and by 2009 Indian producers were producing 1.8 million cars, many of them of export quality (around 330,000 units that year) making India the fourth largest global exporter. It appeared that market opening had forced quality and productivity growth exactly as liberal economists had predicted. However, a closer look tells us that learning still faced contracting failures and the state played an important though different role in co-financing a new and much more successful phase of high-effort learning.

Indian industrial policy had been supporting capability development in cars from the 1950s with the Ambassador produced by Hindustan Motors (part of the Birla group) and the Indian version of a Fiat called the Premier Padmini. Industrial policy was also assisting the manufacture of trucks and buses by Tata and tractors and jeeps by Mahindra and Mahindra. India was also developing tier one and two component producers even if they were not competitive relative to market leaders. The acceleration in the development of competitiveness in the 1980s came about as a result of an accidental train of events set off by Sanjay Gandhi (the prime minister's younger son) who decided in the 1970s to build a 'People's Car': the Maruti. Early attempts to interest Volkswagen in the joint venture were not successful and the project was floundering when Sanjay died in an air crash in 1980 leaving a factory with no immediate prospects of producing anything. The potential loss of prestige for 
the Gandhi name made Indira's government look for effective policies that in effect created new financing instruments for the transfer of technological and organizational capabilities to India. In 1980, the government of India took over the initially private Gandhi family venture and incorporated it in 1981 as a public sector company called Maruti Udyog Ltd. After a long and committed search by top Indian bureaucrats for a foreign technology provider, an agreement was signed with Suzuki in 1982, with the latter taking a 26 per cent equity stake in the company.

Suzuki, then mainly a motorcycle manufacturer with a relatively minor interest in automobiles had the advantage of knowing the Indian market and political system as they had been scouting for business in the motorcycle sector for some time. They recognized that the Indian government was serious about making this project work. The Indian government was effectively willing to open up the protected domestic market with the large rents that had previously been available for domestic learners to a foreign investor if the latter was willing to make a significant investment in transferring capabilities. The domestic market rents were a significant prize for Suzuki and this allowed the Indian government to insist on significant domestic content along the lines required by its Phased Manufacturing Programme, which required 95 per cent local content in five years (Becker-Ritterspach 2007: 9). The joint venture agreement with Suzuki specified 70 per cent non-company value addition of which at least 60 per cent would be locally procured. On the other hand the government's commitment to make the project work was critical for Suzuki. This ensured that the policy changes that were required to make the project succeed could be pushed through. For instance, Suzuki managed to get permission to import gear boxes at low tariffs despite the opposition of the Indian machine tool industry. This made the pace of indigenization feasible while maintaining quality.

The result was a new type of arrangement for financing learning. Suzuki was expected to make significant up-front investments in learning and put in the effort to transfer organizational and technological capabilities to its Indian factory and to the Indian supplier chain. But given the risks and costs Suzuki would almost certainly not have made these significant investments without the implicit public co-financing in the form of the very substantial ex post rents available in the protected domestic market. These potential rewards were great enough to cover Suzuki's investments and risks in financing the learning. The result was incentive compatibility between the state and the recipient of the rent without the necessity of centralized monitoring and enforcement. This was achieved because Suzuki's ability to recover its investments in learning depended on its success in producing the higher quality car to capture the domestic market from existing producers and meeting the domestic content requirements, a condition that was easy to monitor and within the capabilities of the Indian state to enforce. Its effort in managing the learning process was therefore assured and did not have to be monitored in terms of effort or quality of outcomes.

The result was a remarkable transformation of the competitiveness of the Indian automobile sector based on a significant transfer of technological and organizational capabilities. As Maruti's plant at Gurgaon was virtually an empty shell, the Japanese used the organizational structure of their plant at Kosai as the template around which to develop an appropriate Indian organizational structure. The relatively flat Japanese organizational structure could not be replicated in its entirety as Indian managerial hierarchies were resistant to change. But a high effort learning-by-doing process 
resulted in the evolution of a new hybrid organizational structure that was much more efficient than previous Indian organizations. Even more remarkable was the success of Suzuki's supplier development programme, which worked with initially technologically weak and suspicious suppliers to improve their organizational and technological capabilities in order to meet domestic content requirements and reduce input costs for the planned low cost car. The organizational evolution in Gurgaon and throughout the supplier chain involved considerable investments of effort and resources by Suzuki but the results were very positive. By 1983 Maruti-Suzuki had captured 50 per cent of the lucrative protected domestic market as a result of rapid improvements in quality, displacing the slumbering Ambassador from its dominant position in the market. By the late 1990s, Indian tier one component producers began to win international prizes for quality like the Japanese Deming Prize.

Several aspects of the financing instruments and governance capabilities are important for explaining these outcomes. First, the ex post rent was clearly a big enough prize for Suzuki to justify its risky investments in building new capabilities. The prize was access to the large protected domestic market, which remained protected even a decade later in the 1990s and even after India began to formally liberalize. In 199394, three years after liberalization began, the nominal rate of tariffs on automobiles was still 85 per cent, and this only declined to 60 per cent in 2006-07. The effective rate of protection was even higher and actually increased over this period from 88 per cent to 183 per cent because of a decline in the rate of protection for components (Badri and Vashisht 2008: 84-5). If the ex post prize was small, it may not have justified the significant investments and effort in improving technological and organizational capabilities right through the supply chain. Secondly, high ex post rents alone would not have ensured that Suzuki would spend so much effort in transforming the domestic supply chain rather than importing the required inputs. This required enforceable domestic content requirements. Fortunately, the agencies monitoring these outcomes were credible in India and the political settlement was such that foreign companies (even if they wanted to) would have found it difficult to buy political protection if they had failed to deliver on their contractual commitments. India was also lucky in that in the 1980s it was still not constrained by WTO rules (India only joined the WTO in 1995) and it could therefore set domestic content requirements for foreign investors.

The Maruti-Suzuki partnership transformed automobile production in India even though the company did not remain in Indian hands for long. By 1987 Suzuki had increased its equity stake to 40 per cent and by 1992 to 50 per cent. After a protracted conflict over the appointment of the managing director in 1997, the Government of India began to divest its holdings and Suzuki rapidly became the dominant shareholder. However, by then Suzuki had transformed the Indian automobile industry by enhancing the competitiveness of Indian-owned tier one and tier two producers. The increasingly competitive supplier network began to attract foreign and Indian car manufacturers who continued to benefit from the financing arrangement that co-financed learning based on the formula of steep domestic content requirements combined with access to the protected domestic market. In the 1990s, DaimlerChrysler, Fiat, Ford, GM, Honda, Hyundai, Toyota and others followed Suzuki in similar deals. Domestic content requirements made successive technology providers invest further in technology transfer to the supply chain. By 2004, the development of domestically owned tier one capabilities allowed Indian producers 
like Tata and Mahindra and Mahindra to produce Indian branded cars with domestic content ranging from 20 to 100 per cent depending on the model.

\section{The Bangladeshi Garments Industry}

The dramatic growth of the labour-intensive garment industry in Bangladesh in the 1980 s and beyond is another interesting story of how the financing of learning matters, particularly because it is often assumed that learning is not particularly important in low-technology industries like garments. Like automobiles in India, the garments industry in Bangladesh is often portrayed in the popular press as a success story of liberalization. The problem with the comparative advantage narrative is that low wages in Bangladesh did not result in the rapid growth of any other labourintensive sector, and other developing countries with low wages and liberal economic policies have not experienced the dramatic growth observed in the garments sector in Bangladesh.

The answer to these puzzles is the importance of learning even in apparently low technology sectors and the specific ways in which the learning problem was solved in the Bangladeshi garments industry. As in the Indian automobile sector, the growth of the garments industry was associated with the emergence of a successful financing mechanism that created incentives for high-effort learning. One part of the 'instrument' financing learning in the Bangladeshi garment sector was the lucky accident of the Multi-Fibre Arrangement or MFA. This was set up in 1974 to protect US garments and textile manufactures from competition coming from established producers in countries like South Korea and Turkey. The established garment and textile countries were allocated quotas for US imports and as a way of getting the support of other developing countries, quota-free access was offered to less developed countries like Bangladesh that had no garments industry at all. Quota-free access created 'quota rents' for these countries because they could effectively sell at a higher price in US markets after the established exporters had exhausted their quotas. The quota rent was an intended policy outcome, but the intention was to primarily benefit US garments producers who were being threatened by cheaper imports from established producers. The unintended effect was that it potentially provided lossfinancing for learning in the garments sectors in countries like Bangladesh which were not competitive even though their wages were lower than the established garments exporters and much lower compared to the USA.

The quota rent helped to artificially raise Bangladeshi competitiveness for a while but so great was the productivity gap between countries like Bangladesh and more advanced exporters that the MFA on its own would not have been sufficient to enable Bangladesh to produce for exports and engage in learning-by-doing. Indeed, the necessity of additional loss-financing and of appropriate incentives and compulsions for effort is demonstrated by the fact that there were other countries in Africa and Asia that were quota free but did not experience any explosive growth in this sector. However, the MFA raised world prices and reduced the competitiveness gap for Bangladesh and thereby created incentives for Bangladeshi and foreign technology providers to find additional financing for learning in order to scale the remaining competitiveness gap. Fortunately for Bangladesh, it had just begun to acquire a broadbased group of potential investors appropriate for the development of a garments industry. Opportunities for primitive accumulation over the previous decade had helped to create a base of entrepreneurs who could potentially drive growth in the 
sector provided the learning problem could be solved. The solution came in the form of a collaborative agreement between a Bangladeshi company, Desh Garments and the South Korean chaebol Daewoo in 1979. Daewoo had both textile and garments interests, but after its garment production was limited by the MFA it needed to sell its textiles to an offshore partner making garments. This made Daewoo able and willing to transfer the know-how of garments production to an offshore partner.

The founder of Desh was Nurul Quader Khan, an ex-bureaucrat who had clearly benefited from the primitive accumulation of the 1970s and he had become a very rich man with substantial cash to invest. In the 1980s the military-backed government of Zia-ur-Rahman wanted industrialization and the president took the lead in underwriting the collaboration between Desh and Daewoo. As in India, the political commitment of the highest leadership to a particular project was more important than a general policy commitment to industrialization. It signalled to investors that small but specific problems that may otherwise have held up progress would be solved. Desh was responsible for all the physical investments in land and machinery in a modern garment factory in Bangladesh. The agreement with Daewoo was about financing the learning that would transform the factory and its workers into a competitive organization. Desh would literally purchase the requisite know-how from Daewoo, but as in the Suzuki case in India, Daewoo would invest in the learning first and would recover its investment when Desh became competitive. Daewoo did this by hosting at its own expense around 130 mid-level production managers from Bangladesh at its state-of-the-art garments factory in Busan (formerly Pusan). Their learning-by-doing in Busan was critical for acquiring the appropriate organizational and technological capabilities for modern garment manufacturing. Daewoo's investment in financing this learning-by-doing would be paid back in the form of an $8 \%$ royalty on the eventual sales of Desh. The composite financing of the learning thus came from a combination of the MFA quota rents (which reduced the competitiveness gap that Bangladesh had to climb) and further upfront investments by Daewoo that would be repaid by actual sales when Desh achieved competitiveness.

The details of the financing structure help to explain why the stakeholders had strong incentives and compulsions to put in high levels of effort in rapidly transferring the tacit knowledge, particularly about the organization of production. Daewoo had a strong incentive to put in high levels of effort because it needed to sell textiles to Bangladesh, and it needed to recover its investments in learning through royalties from Desh as quickly as possible. With the teachers strongly incentivized, the learning by the students was already half ensured. At the same time, the Bangladeshis who went to Busan had a strong incentive to learn because they had nothing to gain by prolonging their stay in Busan. Moreover, these future managers may already have known that the organizational know-how they were acquiring could also be personally lucrative for them as potential garments entrepreneurs in their own right. Indeed, of the 130 mid-level managers who went to Busan for Desh, 115 eventually set up their own garment factories!

The rate at which learning happened surprised all the participants. Desh had estimated that it would take five years of collaboration with Daewoo to achieve international competitiveness. But so successful was the learning at Busan and subsequently that the deal for cooperation on learning was terminated after less than two years. Desh's growth and that of the Bangladesh garment industry was explosive: Desh grew at 
around 90 per cent a year from 1981 to 1987 . The Bangladesh garment industry grew from an almost zero base in 1980 to around 3500 medium sized firms in 2005 employing more than 3 million workers and accounting for 70 per cent of Bangladesh's exports. One of the ways in which Desh continued to create incentives for the learning effort of its managers was to allow them to leave and set up their own plants if they wished to do so. With large pools of labour, there was no threat of profits being squeezed by wage increases caused by a growing demand for labour in the garments industry as it grew. Moreover, as a critical part of the learning was evolving organizational design, the departure of individual managers was not a critical loss. On the contrary, the growth of an industrial cluster had many advantages in attracting buyers to Bangladesh. Fortunately for Bangladesh, Desh understood its basic economics and it did not create obstacles for managers who wanted to leave. Indeed, this created strong incentives for its managers to continue to experiment and develop organizational and technological capabilities and the company benefited from this ongoing learning and productivity enhancement. By 2010, Bangladesh had become the world's third biggest garments exporter and continued to enjoy doubledigit growth in 2010 despite the global slowdown.

The critical features of the financing instruments and the reasons for their success in financing learning were different in the Bangladeshi garments industry compared to the automobile sector in India. The public rent component here did not come from a protected domestic market but from the MFA, with its sources entirely outside Bangladesh. Bangladeshi producers had no credible mechanism to negotiate its allocation or extension. They rightly saw the MFA as a temporary arrangement and this too supported incentives for effort. The complementary private part of the financing instrument was the collaborative agreement between Desh and Daewoo where the investment in learning was made up-front by the South Korean partner with repayment from the sales of the Bangladeshi firm. This again created strong incentives for the rapid transmission and absorption of the relevant tacit knowledge. The role of the Bangladeshi government was limited but not negligible. The introductions between Desh and Daewoo took place through the direct intervention of President Zia. Informal government support that is perceived to be based on genuine commitment is often more credible than formal support in developing countries. Daewoo, like Suzuki in India found the commitment credible. It assured the foreign partner that administrative problems would be ironed out as indeed they were. Zia's government and its successor pushed through critical institutional innovations like the back-to-back letter of credit (which allowed garments manufactures to finance raw material imports by using their export orders as collateral) and bonded warehouses, both of which reduced the financing cost of importing raw materials and fabrics. Indeed, so successful was the sector that Ronald Reagan imposed quotas on Bangladesh as early as 1985, just a few years after Desh began exporting.

Bangladesh's manufacturing sector now accounts for a similar share of GDP as India, largely because of the garments and textiles industry. The challenge for Bangladesh is to move up the value chain in the garment and textile industry and beyond. However, policy-makers do not generally see the success of the garments sector as an application of technology policy and there has been little progress in designing the types of financing instruments for high-effort learning that is required in other sectors. Upgrading within the garments industry is happening as a result of individual entrepreneurs with deep pockets investing in backward linkages. Bangladesh has 
moved into fabrics and accessories, but the absence of policies to finance learning has constrained upgrading and the development of new sectors like electronics. As in India, the dominant public perception is that competition and comparative advantage explain the success of growth sectors. But the economics of comparative advantage cannot explain why other competitive labour-intensive sectors are not emerging, or why other poor countries that stood to gain from MFA did not in fact do so. The examination of the garments takeoff shows that learning and tacit knowledge transfer were financed by a combination of private investments and public rents, and that the financing instruments were structured to create strong incentives for effort. The challenge is to design similarly effective learning processes in other sectors in Bangladesh and elsewhere.

\section{Conclusion}

An examination of successful growth sectors in the Indian subcontinent shows the importance of addressing the contracting failures affecting learning. The standard instruments of centralized industrial policy performed weakly in the past because they could not ensure high levels of effort given the political settlements in these countries. The ability of South Asian states (and perhaps states in developing countries in general) to withdraw targeted rents from domestic firms was too weak to be a credible threat that could induce sustained effort in learning. The examples from India and Bangladesh suggest that alternative mechanisms of financing that are credible in the context of their political settlements have to be sought and that in principle such financing instruments do exist. Sector-specific financing instruments have fared much better in the period after 1980, and explain the success of critical sectors.

In both our sectors publicly created rents were important complements to private investment in learning. At the same time, private investments were necessary to create the incentives and compulsions for effort in contexts where the political settlement limited the state's disciplining capabilities. In the Indian automobile industry, public policy created rents in the protected domestic market that indirectly financed learning. In the Bangladeshi garment industry, the public policy creating rents was located in the international trade architecture in the form of the MFA. Neither set of rents would necessarily play a positive role in inducing learning if they existed on their own. Indeed, India's protected domestic market for automobiles did not induce anyone to aspire to global competitiveness. However, combined with the right type of private co-financing and some additional enforceable conditions, the public rents achieved remarkable results. Sadly, the public policies that created these particular rents in automobiles and garments would now be precluded by WTO rules. However, in the absence of any public rents for learners, the competitiveness gap in most sectors in South Asia and contracting difficulties would be likely to preclude purely private solutions to learning. One set of policy challenges is therefore to create public rents within WTO rules for sharing the costs of learning when private investors are unwilling to undertake the entire investment in learning on their own. If WTO rules prove to be too constraining for financing learning in developing countries, the rules need to be re-examined.

Given the political settlements in South Asian countries, centralized public strategies of financing learning failed in the past because high levels of effort could not be enforced. The second feature of our successful learning cases was therefore the 
critical role of private investments complementing the public financing of learning. The design of the financing instruments ensured high levels of effort because those responsible for organizing the learning were investing their own money first. Prolonging the learning process through satisficing strategies was unlikely to be a dominant strategy in this case. Instead, strong incentives and compulsions were created for high levels of effort in transferring the tacit knowledge quickly. Public cofinancing enhanced the ex post rewards and thereby reduced the risk facing these investors, inducing them to invest in financing learning in the presence of contracting failures. In both cases, the private investors who were financing the learning were also providing the organizational and technological knowhow. The investors therefore had a good idea of the knowledge that needed to be transferred and it was their assessment that the ex post rewards including the public rents promised satisfactory returns on their investments of resources and effort in ensuring the transfer.

Thus, by combining public and private financing and structuring the private investments appropriately, the centralized monitoring and disciplining of learning rents was no longer necessary. The public rents succeeded in ensuring that private investments in learning were forthcoming and private pre-commitment ensured high levels of effort. The evidence from other sectors in India and Bangladesh suggests that capability development and growth has generally been slow in sectors that did not enjoy this combination of public co-financing of private learning. Clearly, the contracting failures affecting learning remain important. In these two sectors and a number of others, serendipitous combinations of public rents and private investments were sufficient to develop the organizational and technological capabilities necessary for achieving competitiveness. One challenge facing the construction of deliberate policy for other sectors is to calibrate the public support so that the ex post reward does not give too many free handouts to private investors who may have invested with lower incentives, but at the same time provide sufficient incentives for a successful outcome.

Finally, some political and governance conditions were important in both cases, highlighting that every response to a contracting failure has specific enforcement and governance requirements. A common feature of both our cases was that for different reasons the top political leaderships were committed to the success of the particular project. This is likely to be a particularly important condition in developing countries where the overall governance environment is weak and success may depend on political leaders supporting particular projects. The political commitment may make more credible the monitoring and enforcement of critical contracts. In the Indian case the monitoring and enforcement of domestic content requirements was never doubted by Suzuki. In Bangladesh Daewoo and Desh were confident that back-to-back letters of credit and bonded warehouses would come through and that their specific profitsharing contract would be enforceable. These requirements are much less demanding than the expectation that some central agency will monitor performance and reallocate resources, but nonetheless they are governance requirements. The specific details of the financing instruments, political conditions and governance requirements in our two cases are obviously not directly replicable for other sectors or countries. Nevertheless, they suggest that in principle learning can be financed using instruments that generate incentives for effort that are credible even in political settlements where centralized industrial policy instruments are not likely to be effective. 


\section{References}

Atkinson, Anthony B. and Joseph E. Stiglitz 1969. A New View of Technological Change, The Economic Journal 79 (315): 573-78.

Badri, Narayanan G. and Pankaj Vashisht 2008. Determinants of Competitiveness of the Indian Auto Industry. Working Paper No. 201. Indian Council for Research on International Economic Relations: New Delhi.

Becker-Ritterspach, Florian 2007. Maruti-Suzuki's Trajectory: From a Public Sector Enterprise to a Japanese Owned Subsidiary. 15th GERPISA International Colloquium, 20-22nd June. GERPISA International Network: Paris. Available $<$ www.becker-ritterspach.de/pdf/Gerpisa\%20Becker-Ritterspach.pdf $>$

Clark, Gregory and Susan Wolcott 2002. One Polity, Many Countries: Economic Growth in India, 1873-2000, in Rodrik, Dani (ed.) Institutions, Integration, and Geography: In Search of the Deep Determinants of Economic Growth, Princeton NJ: Princeton University Press.

Dosi, Giovanni 1988. The Nature of the Innovative Process, in Dosi, Giovanni, Christopher Freeman, Richard R. Nelson, Gerald Silverberg and Luc Soete (eds) Technical Change and Economic Theory, London: Pinter Publishers.

Hausmann, Ricardo and Dani Rodrik 2003. Economic Development as Self Discovery, Journal of Development Economics 72 (2): 603-33. Available HTTP: $<$ http://ksghome.harvard.edu/ drodrik/selfdisc.pdf $>$

Hoekman, Bernard M., Keith E. Maskus and Kamal Saggi 2004. Transfer of Technology to Developing Countries: Unilateral and Multilateral Policy Options. World Bank Policy Research Working Paper No. 3332. World Bank: Washington DC.

Khan, Mushtaq Husain 1995. State Failure in Weak States: A Critique of New Institutionalist Explanations, in Harriss, John, Janet Hunter and Colin M. Lewis (eds) The New Institutional Economics and Third World Development, London: Routledge.

Khan, Mushtaq Husain 1996. The Efficiency Implications of Corruption, Journal of International Development 8 (5): 683-96.

Khan, Mushtaq Husain 1999. The Political Economy of Industrial Policy in Pakistan 1947-1971. SOAS Department of Economics Working Paper No. 98, School of Oriental and African Studies, University of London.

Khan, Mushtaq Husain 2000a. Rents, Efficiency and Growth, in Khan, Mushtaq H. and K.S. Jomo (eds) Rents, Rent-Seeking and Economic Development: Theory and Evidence in Asia, Cambridge: Cambridge University Press.

Khan, Mushtaq Husain 2000b. Rent-seeking as Process, in Khan, Mushtaq H. and K.S. Jomo (eds) Rents, Rent-Seeking and Economic Development: Theory and Evidence in Asia, Cambridge: Cambridge University Press. 
Khan, Mushtaq Husain 2009. Learning, Technology Acquisition and Governance Challenges in Developing Countries. Research Paper Series on Governance for Growth. School of Oriental and African Studies, University of London: London. Available

$<$ https://eprints.soas.ac.uk/9967/1/Learning_and_Technology_Acquisition_internet.pd f>

Khan, Mushtaq Husain 2010. Political Settlements and the Governance of GrowthEnhancing Institutions. Research Paper Series on Governance for Growth. School of Oriental and African Studies, University of London: London. Available $<\underline{\text { http://eprints.soas.ac.uk/9968/1/Political_Settlements internet.pdf }>}$

Khan, Mushtaq Husain 2012. The Political Economy of Inclusive Growth, in de Mello, Luiz and Mark A. Dutz (eds) Promoting Inclusive Growth: Challenges and Policies, Paris: OECD Publishing. Available $<$ http://www.oecdilibrary.org/economics/promoting-inclusive-growth/the-political-economy-ofinclusive-growth 9789264168305-3-en;jsessionid=4rg80c1r7eqch.delta $>$

Khan, Mushtaq Husain and Stephanie Blankenburg 2009. The Political Economy of Industrial Policy in Asia and Latin America, in Dosi, Giovanni, Mario Cimoli and Joseph E. Stiglitz (eds) Industrial Policy and Development: The Political Economy of Capabilities Accumulation, Oxford: Oxford University Press.

Lall, Sanjaya 1992. Technological Capabilities and Industrialization, World Development 20 (2): 165-86.

Lall, Sanjaya 2000a. Selective Industrial and Trade Policies in Developing Countries: Theoretical and Empirical Issues. Working Paper Series No. 48. Queen Elizabeth House: Oxford.

Lall, Sanjaya 2000b. Skills, Competitiveness and Policy in Developing Countries. Working Paper Series No. 46. Queen Elizabeth House: Oxford.

Lall, Sanjaya 2003. Reinventing Industrial Strategy: The Role of Government Policy in Building Industrial Competitiveness. Working Paper Series No. 111. Queen Elizabeth House: Oxford.

Lancaster, Kelvin J. 1966. A New Approach to Consumer Theory, Journal of Political Economy 74 (2): 132-57.

Murphy, Kevin M., Andrei Shleifer and Robert W. Vishny 1989. Industrialization and the Big Push, Journal of Political Economy 97 (5): 1003-26.

Nelson, Richard R. and Sidney G. Winter 1982. An Evolutionary Theory of Economic Change. Cambridge Mass: Belknap Press of Harvard University Press.

Nurkse, Ragnar 1953. Problems of Capital Formation in Underdeveloped Countries. Oxford: Oxford University Press. 
Pelikan, Pavel 1988. Can the Imperfect Innovation Systems of Capitalism be Outperformed?, in Dosi, Giovanni, Christopher Freeman, Richard R. Nelson, Gerald Silverberg and Luc Soete (eds) Technical Change and Economic Theory, London: Pinter Publishers.

Perez, Carlota and Luc Soete 1988. Catching Up in Technology: Entry Barriers and Windows of Opportunity, in Dosi, Giovanni, Christopher Freeman, Richard R. Nelson, Gerald Silverberg and Luc Soete (eds) Technical Change and Economic Theory, London: Pinter Publishers.

Polanyi, Michael 1967. The Tacit Dimension. Garden City NY: Doubleday Anchor.

Rosenstein-Rodan, Paul N. 1943. Problems of Industrialisation of Eastern and SouthEastern Europe, The Economic Journal 53 (210/211): 202-11.

Scitovsky, Tibor 1954. Two Concepts of External Economies, Journal of Political Economy 62 (2): 143-51.

Stiglitz, Joseph E. 1987. Learning to Learn, Localized Learning and Technological Progress, in Dasgupta, Partha and Paul Stoneman (eds) Economic Policy and Technological Development, Cambridge: Cambridge University Press.

Stiglitz, Joseph E. 2007. Making Globalization Work. London: Penguin.

Sutton, John 2005. Competing in Capabilities: An Informal Overview. London School of Economics: London. Available $<$ http://personal.lse.ac.uk/SUTTON/competing_capabilities_informal_washington.pdf $>$

Sutton, John 2007. Quality, Trade and the Moving Window: The Globalization Process, The Economic Journal 117 (524): F469-98. 